\title{
Ameliorative impact of cinnamon against high blood pressure; an updated review
}

\author{
Leila Mahmoodnia ${ }^{1}$, Esmat Aghadavod ${ }^{2}$, Mahmoud Rafieian-Kopaei $^{3^{*}}$ \\ ${ }^{1}$ Department of Internal Medicine, Shahrekord University of Medical Sciences, Shahrekord, Iran \\ ${ }^{2}$ Research Center for Biochemistry and Nutrition in Metabolic Diseases, Kashan University of Medical Sciences, Kashan, Iran \\ ${ }^{2}$ Medical Plants Research Center, Shahrekord University of Medical Sciences, Shahrekord, Iran
}

\section{A R T I C L E I N F O}

Article Type:

Review

\section{Article History:}

Received: 9 October 2016

Accepted: 18 January 2017

Published online: 1 February 2017

Keywords:

Cinnamon

High blood pressure

Hypertension

Type II diabetes mellitus

\begin{abstract}
A B S T R A C T
High blood pressure (BP) or hypertension is a vital people health challenge in both developed countries and economically developing ones. By commencing a few novel food habits, containing counting calories and observing portion sizes, individuals can lower their BPs and modulate administered drugs to regulator high BP better. Additionally, some herbal drugs may be able to lower BP. Over the past centuries, cinnamon has been consumed as a traditional remedy in China. Cinnamon, the everlasting tree of tropical medication, belongs to the Lauraceae clan. In fact, cinnamon is one of the most main spices consumed daily by people globally. The accessible in vitro and preclinical data suggest that cinnamon has anti-antioxidant, anti-inflammatory, antitumor, antimicrobial, cholesterol-lowering, cardiovascular protecting, and immuno-modulatory effects. Likewise, numerous researches have demonstrated its beneficial effects on BP. In this review, therapeutic effects of cinnamon particularly on BP and on patients having type II diabetes mellitus will be reviewed.
\end{abstract}

\begin{abstract}
Implication for health policy/practice/research/medical education:
Cinnamon and constituents of cinnamon have been presented to have helpful effects on essentially all of the agents related to metabolic syndrome, containing blood glucose regulation, insulin sensitivity, lipids, inflammation subsiding, antioxidant property, high blood pressure and body weight reduction efficacy.

Please cite this paper as: Mahmoodnia L, Aghadavod E, Rafieian-Kopaei M. Ameliorative impact of cinnamon against high blood pressure; an updated review. J Renal Inj Prev. 2017;6(3):171-176. DOI: 10.15171/jrip.2017.33.
\end{abstract}

\section{Introduction}

Blood pressure (BP) is controlled, moment by moment, by the balance between heart outputs against total peripheral resistance and alters depending on position, activity, emotional state, and relative health/disease conditions. It is controlled by the brain through both the endocrine and nervous systems (1). On the other hand, BP is not stable and spontaneous variations in BP exist (2). Disorders of $\mathrm{BP}$ control include; low BP, high BP and BP that exhibits in excessive or in abnormal fluctuation (1). In 1987, Parati et al provided the first data of an association between 24 hours BP variability (BPV) and the intensity of organ injury (3). Lastly, it was discovered that, an optimum level of $\mathrm{BP}$ is associated with less organ injury than patients in with high $\mathrm{BP}(3)$.

Over the past 20 years dietary fiber has appeared as a leading dietary influence in the inhibition and treatment of chronic diseases. High fiber consumptions are related to, decreased risk of certain forms of cancer, lower risk of coronary heart disease, lower serum cholesterol concentrations, decreased BP, better glycemic control, increased weight control and recovered gastrointestinal function (4). As a matter of fact, herbal medicines with high quantities of phytochemicals have been emerged to have beneficial influences on $\mathrm{BP}$, anthropometric measures and endothelial function (5).

Equally important, cinnamon has been consumed in several cultures for periods as a spice and also as a traditional herbal medicine (6). In other words, cinnamon, a plant of the laurel species Lauraceae, as a spice in numerous cultures for centuries (6), has been consumed in China for thousands of years against many diseases, for instance the "thirsty disease," which was an old expression for diabetes in China before the expression 
diabetes mellitus was created in modern medicine (7). In addition, some evidences recommend that cinnamon may be efficient in the supportive remedy of cancer, infectious diseases, and complaints related with modern life style owing to its antioxidant, antimicrobial, anti-inflammatory, and BP-lowering properties (6).

The bark is the only ingredient of this plant that is consumed in the function of a spice or for medical intentions (Cinnamomi cortex) (8). As a matter of fact, the bark of diverse cinnamon species is one of the most important and general spices used universal not only for cooking but also in traditional and present medicines. On the whole, approximately 250 species have been recognized among the cinnamon genus, with trees being distributed all over the Earth (9). In addition, Cinnamon bark possesses catechins and procyanidins (10). The constituents of procyanidins contain both procyanidin A-type and B-type bonds (11). These procyanidins are taken out from cinnamon and berries. They also own antioxidant activities (11).

In the same way, the most important ingredients of cinnamon is trans-cinnamaldehyde or cinnamaldehyde (Figure 1), which exists in the essential oil, therefore donating to the fragrance and to the diverse biological activities perceived with cinnamon (12).

Equally important, in 2008, a study by Chang et al on Cinnamomum osmophloeum demonstrated that the essential oil from cinnamon leaves includes a high level of cinnamon. Subsequently, C. osmophloeum is also used as a replacement spice for $C$. cassia (13). One of the main constituents of essential oil obtained from C. zeylanicum termed (E)-cinnamaldehyde has an antityrosinase activity (14), whereas cinnamaldehyde is the main compound accountable for this activity (15).

The purpose of this paper is to review recent researches in the therapeutic efficient of cinnamon particularly on high $\mathrm{BP}$ disease, and patients with prediabetes and type 2 diabetes mellitus (T2DM).

\section{Materials and Methods}

For this review, we used a variety of sources by searching through Web of Science, PubMed, EMBASE, Scopus and directory of open access journals (DOAJ). The search was performed using combinations of the following key words and or their equivalents such as; cinnamon, high blood pressure, hypertension and type II diabetes mellitus.

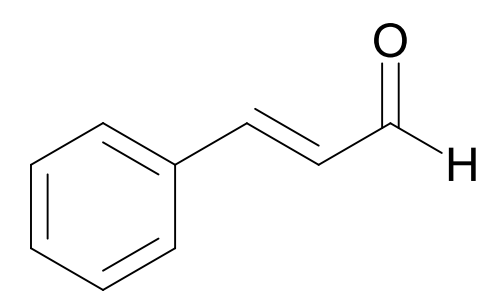

Figure 1. Structure of trans-cinnamaldehyde or cinnamaldehyde.

\section{Results}

The therapeutic effects of cinnamon

Cinnamon has a long history of consumption in traditional medicine, but there is few evidences on its interacted pathophysiological mechanisms (16).

As above noted, cinnamon is a spice generally used in cooking that derives from the bark of the cinnamon tree. When the bark is eliminated, it is termed cinnamon stick. It has also been consumed as medicine in traditional curing systems for ages. The fresh cinnamon sticks are crushed to prepare tea, to cook into sprinkle on toast, desserts or cereal. Since it may act together with certain medicines, it is notable to check other drugs before using cinnamon (17).

Actually, cinnamon is an aromatic spice that is a good source of iron, calcium and manganese. It can help relieve indigestion pain and toothaches. This creates it ideal for cooking and remedial use (18). In addition, cinnamon is highly disinfected, because it has a high phenolic content, which creates it effective against toothache and as a mouthwash remedy. Also, cinnamon stick is chewed to reduce toothache and refresh the breath. If it is ground and inserted to water and added fresh mint can be gurgled as a mouthwash. Likewise, cinnamon aids weak digestion, and aids ease muscle pain, arthritis and rheumatism, thus chewing a cinnamon stick, preparing tea with it or crushing the cinnamon stick and inserting it to food can be help the people who suffer from any of these disorders (18). In the same way, cinnamon is a coagulant and stops bleeding (19). It also enhances the blood circulation in the advances tissue renewal and uterus (20).

On the whole, this plant performs a key role as a spice, but its essential oils and other ingredients also have important activities, counting antifungal (21), antimicrobial (22), antidiabetic (23), antioxidant (24), anti-inflammatory (25), antitermitic (25), antimycotic (26), nematicidal (27), insecticidal (26), mosquito larvicidal (28), and anticancer activities (29).

\section{The therapeutic effect of cinnamon on hypertension}

More than 20 years have passed since the national high BP education program was started and its early report on the detection, assessment and remedy of patients with hypertension was published (30).

Hypertension is a critical public health challenge in both developed countries and economically developing ones owing to its high prevalence and concomitant rise in risk of disorder (31). It is the most significant modifiable risk agent for cerebrovascular, cardiovascular, and renal disease (32). The relative risk assessment collaborating group has recognized hypertension as the leading worldwide risk agent for mortality and as the third leading risk agent for disease burden (33). While hypertension is well-known as a main cause of morbidity and mortality in the economically developed globe, the significance of hypertension in economically developing countries is less 
well created (32). Considerable numbers of persons with hypertension are unaware of their situation and, among those with identified hypertension, treatment is frequently inadequate. Measures are needed at a population level to inhibit the development of hypertension and to develop awareness, remedy and control of hypertension in the society (32).

The reported extensiveness of high BP is varied worldwide, with the highest level in Poland (68.9\% in men and 72.5\% in women subjects) and the lowest level in rural India (3.4\% in men and $6.8 \%$ in women subjects). Awareness of high BP was about $46 \%$ of the examinations and was different in several countries (for example $25.2 \%$ in Korea and $75 \%$ in Barbados, also $10.7 \%$ in Mexico and $66 \%$ in Barbados). Furthermore, the subjects on antihypertensive medicines are also different from 5.4\% in Korea to 58\% in Barbados (32).

In the same way, the United States national high BP education program coordinating committee has advised six approaches with proven effectiveness for the initial prevention of hypertension (34). These interventions contain dietary sodium reduction, weight loss, physical activity, limitation in alcohol consumption, potassium supplementation and variation of whole diets (34).

Therefore, the influence of dietary composition on BP is a subject of public health significance (35). Dietary approaches to stop hypertension (DASH) experimentally demonstrated that a regimen which emphasizes on vegetables, fruits, and low-fat dairy crops, and contains whole grains, fish, poultry, and nuts, that includes only small quantities of sweets, red meat, and sugar-containing beverages, and which includes decreased quantities of total and saturated fat and cholesterol lowers BP considerably both in persons with hypertension and those without hypertension, as contrasted with a usual diet in the United States (36).

In animal investigations, cinnamon has been appeared to reduce BP. In 1975, Mastoshi and Shingo showed that cinnamaldehyde creates hypotensive effects, which are perhaps due to outlying vasodilatation in guinea pigs and anesthetized dogs (37). The vasodilatation caused by cinnamaldehyde in dogs lasted and stayed over the recovery time of the fall in BP to the baseline (38). In 2011, Xue et al indicated that cinnamaldehyde increased rat vascular smooth muscle in an endotheliumindependent method. The capability of cinnamaldehyde in vasodilatory performance might be due to inhibition of both $\mathrm{Ca}^{2+}$ invasion and $\mathrm{Ca}^{2+}$ discharge (39). Likewise, cinnamaldehyde prevents the development of hypertension in types I and II diabetes by reducing vascular contractility, as well as its insulinotropic effect in insulin fault (40).

In the other words, cinnamon $(8 \% \mathrm{w} / \mathrm{w})$ in the regimen decreased the systolic BP of spontaneously hypertensive rats (SHR) consuming sucrose-containing regimen to nearly the same levels as SHR consuming regimens including non-sucrose. Additionally, the presence of cinnamon in the diet reduced the systolic BP of SHR consuming a non-sucrose-containing regime, proposing that cinnamon degrades more than just sucrose-induced $\mathrm{BP}$ raises (6).

Besides, C. cassia bark influences on the cardiovascular and blood system (41). In 1995, Zhou et al published a paper in which they described that the actions of $C$. cassia bark was related to the amount of atrial natriuretic factor (ANF) in the plasma of mice (42). ANF performs to decrease the sodium, water, and adipose put in the circulatory system, thereby reducing BP (6). Likewise, ANF was considerably higher in the plasma of mice next giving C. cassia orally, compared with regulator $(P<0.001)(6)$.

On the whole, accessible in vivo data powerfully support the hypothesis that cinnamon lowers systolic BP in experimental animals (6).

\section{Cinnamon on BP regulation in patients with pre-diabetes and $T 2 D M$}

Hypertension is very common in persons with T2DM, influencing up to $60 \%$ of the people (43). In 2006, Ziegenfuss et al (44) and, in 2010, Akilen et al (45) exhibited a significant decrease in systolic BP or diastolic BP followed by a considerable reduction in glycemic signs (fasting plasma glucose or $\mathrm{HbAlc}$ ).

Insulin resistance and T2DM are rapidly rising throughout the world. In 1990, it was stated that compounds discovered in cinnamon (Cinnamon cassia) had insulinpotentiating attributes and might be involved in the improvement of the signs and indications of diabetes and cardiovascular disorder associated to insulin resistance (46). Cinnamon has been reported to positively affect the insulin system (45). Several combinations of essential oils counting cinnamon, fenugreek, cumin, and oregano have been exhibited to increase insulin sensitivity in vitro trials. In 2005, Talpur et al realized that the capability to alter systolic BP in rat models was the most sensitive primary index of insulin sensitivity (47). The merged essential oils reduced circulating glucose concentrations and systolic BP in both Zucker fatty rats (an example of insulin resistance and fatness) and SHR (an example of genetic hypertension), recommending that these natural products are able to increase insulin sensitivity (6).

Utilization of cinnamon (short term) is related with a notable decrease in systolic BP and diastolic BP. Even though cinnamon exhibits hopeful influences on BPdropping potential, it would be premature to advise cinnamon for BP control owing to the limited number of investigations available. Therefore, a long-term, sufficiently powered randomized controlled trial (RCT) containing a larger number of patients is required to assess the clinical potential of cinnamon on BP regulator among patients with T2DM (48).

\section{Discussion}

Spices, consumed in Indian cooking, have a long record of use as drugs to prevent and treat diseases. Many investigates 
have proved that spices can be useful drugs, but the main challenge is now to provide scientific data and reasonable mechanisms for their remedial responses (49).

Cinnamomum is a middle sized evergreen tree, about 10$15 \mathrm{~m}$ tall, innate to Southern India and Sri Lanka (50), but also is found in central to Burma, southern mainland China, Cambodia, Malaysia, Taiwan and Indonesia (51). In brief, the tree is dispensed in regions between 500 and $1500 \mathrm{~m}$ in height. Its bark has been extensively used as a flavoring and spice agent for periods. Cinnamon has been suggested to have many pharmacological attributes, containing antimicrobial effects and antioxidant activity (52).

Numerous reports have distributed with the numerous attributes of cinnamon in the forms of, essential oils, bark, bark powder, flavonoids, phenolic compounds, and isolated constituents. Each of these attributes plays a vital role in the improvement of persons health (53). In fact, Akilen et al found that the regimen of cinnamon decreased both systolic and diastolic BP in T2DM from 132.6 to $129.2 \mathrm{~mm} \mathrm{Hg}$ and 85.2 to $80.2 \mathrm{~mm} \mathrm{Hg}$, one-toone (45). In spite of this, the exact BP-lowering procedure of cinnamon is still unknown and new studies are required to explain this issue (54).

As a matter of fact, cinnamon and constituents of cinnamon have been presented to have helpful effects on essentially all of the agents related with metabolic syndrome, containing glucose, insulin sensitivity, lipids, inflammation, antioxidants, high BP, and body weight. In addition, agents associated with related disorders, containing stroke, Alzheimer's disease, and cancer, have also been exhibited to be improved by cinnamon and its constituents in in vitro findings (55).

The influence of cinnamon on systolic BP and diastolic $\mathrm{BP}$ at baseline and post-interference is exhibited in Table 1. Two RCTs exhibited significant decrease in systolic BP (45), and another study showed marginally significant decrease in systolic BP (56). In contrast, two RCTs did not exhibit any significant decrease in diastolic BP (44), in spite of this, one study exhibited significant decrease in diastolic BP (45).

On the whole, up to now, there have been numerous suggested procedures of cinnamon's action, these contain postponed gastric emptying, risen glycogen synthesis by motivating glycogen synthase, and preventing glycogen synthase kinase $3 \mathrm{~b}$. But no one suggested a perfect understanding (54).

\section{Conclusion}

The present review provides additional evidence with respect to the cinnamon, as a spice in everyday life and devoid of any side effects, can be consumed as a remedy to lower BP levels particularly in patients with T2DM, although, so far, its mechanisms function is unclear.

\section{Authors' contribution}

LM and EA searched and gathered the related articles. LM prepared the draft. MRK edited the final manuscript. All authors read and signed the final paper.

\section{Conflicts of interest}

The authors declare no conflicts of interest.

\section{Ethical considerations}

Ethical issues (including plagiarism, data fabrication, double publication) have been completely observed by the authors.

\section{Funding/Support}

None.

\section{References}

1. Understanding blood pressure readings. American Heart Association website. http://www.heart.org/HEARTORG/

Table 1. Influence of cinnamon on systolic and diastolic BP

\begin{tabular}{|c|c|c|c|c|c|c|c|}
\hline \multirow[b]{2}{*}{ Research } & \multirow[b]{2}{*}{ Changing } & \multicolumn{2}{|c|}{ Cinnamon } & \multicolumn{2}{|c|}{ Placebo } & \multirow[b]{2}{*}{$P$ value } & \multirow[b]{2}{*}{ Calculations } \\
\hline & & Baseline & $\begin{array}{c}\text { Post- } \\
\text { Intervention }\end{array}$ & Baseline & $\begin{array}{c}\text { Post- } \\
\text { Intervention }\end{array}$ & & \\
\hline \multirow[t]{2}{*}[\mathrm{C}=30,P=28]{$(45)$} & & & & & & & \multirow{2}{*}{$\begin{array}{l}\text { Systolic BP and diastolic BP notably } \\
(P<0.05) \text { decreased after } 12 \text { weeks in the } \\
\text { cinnamon group contrasted to placebo. }\end{array}$} \\
\hline & Diastolic BP & $8.5 \pm 6.45$ & $81 \pm 5.80$ & $87 \pm 8.82$ & $86 \pm 8.08$ & $<0.001$ & \\
\hline \multirow[b]{2}{*}[\mathrm{C}=12,P=10]{$(44)$} & Systolic BP & $133 \pm 14$ & $128 \pm 18$ & $133 \pm 22$ & $142 \pm 20$ & $<0.001$ & \multirow{2}{*}{$\begin{array}{l}\text { Studies in the cinnamon group appeared } \\
\text { a considerable decrease }(P<0.05) \text { in } \\
\text { systolic BP contrasted to placebo. No } \\
\text { considerable changes were detected in } \\
\text { diastolic BP. }\end{array}$} \\
\hline & Diastolic BP & $83 \pm 6$ & $84 \pm 9$ & $83 \pm 14$ & $86 \pm 12$ & $<0.32$ & \\
\hline \multirow{2}{*}[C=29,P=30]{$(56)$} & Systolic BP & $140 \pm 14$ & $137.1 \pm 14.7$ & $130.7 \pm 12$ & $132.7 \pm 10.3$ & 0.06 & \multirow{2}{*}{$\begin{array}{l}\text { Systolic BP values reduced in the } \\
\text { cinnamon group and raised in the } \\
\text { placebo group This difference of systolic } \\
\text { BP was only slightly significant. No } \\
\text { significant changes were detected in } \\
\text { diastolic BP. }\end{array}$} \\
\hline & Diastolic BP & $78.6 \pm 9.5$ & $75.9 \pm 10.4$ & $75 \pm 9.3$ & $73.7 \pm 7.0$ & 0.68 & \\
\hline
\end{tabular}

Abbreviations: C, cinnamon; $\mathrm{P}$, placebo; BP, blood pressure.

All results are stated in $\mathrm{mmHg}$. Data shown as mean $+\mathrm{SD}$. $P$ values present the changes (baseline vs. post-intervention) between cinnamon and placebo groups. 
Conditions/HighBloodPressure/AboutHighBloodPressure/ Understanding-Blood-Pressure-Readings_UCM_301764_ Article.jsp\#.WJLfG_LMitM

2. Su DF, Miao CY. Blood pressure variability and organ damage. Clin Exp Pharmacol Physiol. 2001;28:709-15.

3. Parati G, Pomidossi G, Albini F, Malaspina D, Mancia G. Relationship of 24-hour blood pressure mean and variability to severity of target-organ damage in hypertension. J Hypertens. 1987;5:93-8.

4. Anderson JW, Smith BM, Gustafson NJ. Health benefits and practical aspects of high-fiber diets. Am J Clin Nutr. 1994;59:1242S-7S.

5. Azimi P, Ghiasvand R, Feizi A, Hosseinzadeh J, Bahreynian M, Hariri M, et al. Effect of cinnamon, cardamom, saffron and ginger consumption on blood pressure and a marker of endothelial function in patients with type 2 diabetes mellitus: A randomized controlled clinical trial. Blood Press. 2016;25:133-40. doi: 10.3109/08037051.2015.1111020.

6. Gruenwald J, Freder J, Armbruester N. Cinnamon and health. Crit Rev Food Sci Nutr. 2010;50:822-34. doi: 10.1080/10408390902773052.

7. Lu T, Sheng H, Wu J, Cheng Y, Zhu J, Chen Y. Cinnamon extract improves fasting blood glucose and glycosylated hemoglobin level in Chinese patients with type 2 diabetes. Nutr Res. 2012;32:408-12. doi: 10.1016/j.nutres.2012.05.003.

8. Blumenthal M, Busse W, Goldberg A, Gruenwald J, Hall T, Riggins C, et al. The Complete German Commission E Monographs-Therapeutic Guide to Herbal Medicines. Texas: American Botanical Council, Austin, Texas; 1998;

9. Sangal A. Role of cinnamon as beneficial antidiabetic food adjunct: a review. Adv Appl Sci Res. 2011;2:440-50.

10. Nonaka GI, Morimoto S, Nishioka I. Tannins and related compounds. Part 13. Isolation and structures of trimeric, tetrameric, and pentameric proanthicyanidins from cinnamon. J Chem Soc Perkin Trans. 1. 1983:2139-45. doi: 10.1039/P19830002139.

11. Peng X, Cheng KW, Ma J, Chen B, Ho CT, Lo C, et al. Cinnamon bark proanthocyanidins as reactive carbonyl scavengers to prevent the formation of advanced glycation endproducts. J Agric Food Chem. 2008;56:1907-11.

12. Yeh HF, Luo CY, Lin CY, Cheng SS, Hsu YR, Chang ST. Methods for thermal stability enhancement of leaf essential oils and their main constituents from indigenous cinnamon (Cinnamomum osmophloeum). J Agric Food Chem. 2013;61:6293-8. doi: 10.1021/jf401536y.

13. Chang CW, Chang WL, Chang ST, Cheng SS. Antibacterial activities of plant essential oils against Legionella pneumophila. Water Res. 2008;42:278-86.

14. Marongiu B, Piras A, Porcedda S, Tuveri E, Sanjust E, Meli M, et al. Supercritical CO2 extract of Cinnamomum zeylanicum: chemical characterization and antityrosinase activity. J Agric Food Chem. 2007;55:10022-7.

15. Chou ST, Chang WL, Chang CT, Hsu SL, Lin YC, Shih Y. Cinnamomum cassia essential oil inhibits $\alpha$-MSH-induced melanin production and oxidative stress in murine B16 melanoma cells. Int J Mol Sci. 2013;14:19186-201.

16. National Institutes of Health. Herbs at a glance. Cinnamon https://www.cinnamonvogue.com/DOWNLOADS/ Cinnamon\%20Side\%20Effects.pdf. Accessed September 7, 2015.

17. Mccarthy K. The Benefits of Cinnamon Sticks 2015. http:// www.livestrong.com/article/267542-the-benefits-ofcinnamon-sticks/. Published 2015.
18. Burns E. What to Do With Cinnamon Sticks? https:// www.leaf.tv/articles/what-to-do-with-cinnamon-sticks/. Published 2016.

19. Hossein N, Abolfazl M, Mahdi S, Ali K. Effect of Cinnamon zeylanicum essence and distillate on the clotting time. J Med Plants Res. 2013;7:1339-43.

20. Minich S, Msom L. Chinese Herbal Medicine in Women's Health. Women's Health; 2008.

21. Wang SY, Chen PF, Chang ST. Antifungal activities of essential oils and their constituents from indigenous cinnamon (Cinnamomum osmophloeum) leaves against wood decay fungi. Bioresour Technol. 2005;96:813-8.

22. Chang ST, Chen PF, Chang SC. Antibacterial activity of leaf essential oils and their constituents from Cinnamomum osmophloeum. J Ethnopharmacol. 2001;77:123-7.

23. Lu Z, Jia $Q$, Wang $R$, Wu X, Wu Y, Huang C, et al. Hypoglycemic activities of A-and B-type procyanidin oligomer-rich extracts from different Cinnamon barks. Phytomedicine. 2011;18:298-302. doi: 10.1016/j. phymed.2010.08.008.

24. Mathew S, Abraham TE. In vitro antioxidant activity and scavenging effects of Cinnamomum verum leaf extract assayed by different methodologies. Food Chem Toxicol. 2006;44:198-206.

25. Tung YT, Yen PL, Lin CY, Chang ST. Anti-inflammatory activities of essential oils and their constituents from different provenances of indigenous cinnamon (Cinnamomum osmophloeum) leaves. Pharm Biol. 2010;48:1130-6.

26. Cheng SS, Liu JY, Huang CG, Hsui YR, Chen WJ, Chang ST. Insecticidal activities of leaf essential oils from Cinnamomum osmophloeum against three mosquito species. Bioresour Technol. 2009;100:457-64.

27. Kong JO, Lee SM, Moon YS, Lee SG, Ahn YJ. Nematicidal activity of cassia and cinnamon oil compounds and related compounds toward Bursaphelenchus xylophilus (Nematoda: Parasitaphelenchidae). J Nematol. 2007;39:31.

28. Cheng SS, Liu JY, Tsai KH, Chen WJ, Chang ST. Chemical composition and mosquito larvicidal activity of essential oils from leaves of different Cinnamomum osmophloeum provenances. J Agric Food Chem. 2004;52:4395-400.

29. Kwon HK, Hwang JS, So JS, Lee CG, Sahoo A, Ryu JH, et al. Cinnamon extract induces tumor cell death through inhibition of NFKB and AP1. BMC Cancer. 2010;10:392. doi: 10.1186/1471-2407-10-392.

30. Frohlich ED. The fifth Joint National Committee report on the detection, evaluation and treatment of high blood pressure. J Am Coll Cardiol. 1993;22:621-2.

31. He J, Whelton PK. Epidemiology and prevention of hypertension. Med Clin North Am. 1997;81:1077-97.

32. Kearney PM, Whelton M, Reynolds K, Whelton PK, He J. Worldwide prevalence of hypertension: a systematic review. J Hypertens. 2004;22:11-9.

33. Ezzati M, Lopez AD, Rodgers A, Vander Hoorn S, Murray CJ. Selected major risk factors and global and regional burden of disease. Lancet. 2002;360:1347-60.

34. Whelton PK, He J, Appel LJ, Cutler JA, Havas S, Kotchen TA, et al. Primary prevention of hypertension: clinical and public health advisory from The National High Blood Pressure Education Program. JAMA. 2002;288:1882-8. doi: 10.1001/jama.288.15.1882.

35. Sacks FM, Svetkey LP, Vollmer WM, Appel LJ, Bray GA, Harsha D, et al. Effects on blood pressure of reduced dietary sodium and the dietary approaches to stop hypertension 
(DASH) diet. N Engl J Med. 2001;344:3-10.

36. Appel LJ, Moore TJ, Obarzanek E, Vollmer WM, Svetkey LP, Sacks FM, et al. A clinical trial of the effects of dietary patterns on blood pressure. N Engl J Med. 1997;336:111724.

37. Mastoshi $\mathrm{H}$, and Shingo Y. Pharmacological studies on Chinese cinnamon. II. Effects of cinnamaldehyde on the cardiovascular and digestive systems. Chem Pharm Bull. 1975;23:941-7.

38. Harada M, Hirayama Y, Yamazaki R. Pharmacological studies on chinese cinnamon. V. Catecholamine releasing effect of cinnamaldehyde in dogs. J Pharmacobiodyn. 1982;5:539-46.

39. Xue YL, Shi HX, Murad F, Bian K. Vasodilatory effects of cinnamaldehyde and its mechanism of action in the rat aorta. Vasc Health Risk Manag. 2011;7:273-80. doi: 10.2147/VHRM.S15429.

40. El-Bassossy HM, Fahmy A, Badawy D. Cinnamaldehyde protects from the hypertension associated with diabetes. Food Chem Toxicol. 2011;49:3007-12. doi: 10.1016/j. fct.2011.07.060.

41. Chen Y. Pharmacological studies of Cinnamomum cassia bark. Part I. Effects on the blood and cardiovascular system (Chinese). Zhong Yao Tong Bao. 1981;6:32-4.

42. Zhou L, Chen Z, Chen J. Effect of wu lin powder and its ingredients on atrial natriuretic factor level in mice (Chinese). Zhongguo Zhong Xi Yi Jie He Za Zhi. 1995; 15:36-7.

43. Vijan S, Hayward RA. Treatment of hypertension in type 2 diabetes mellitus: blood pressure goals, choice of agents, and setting priorities in diabetes care. Ann Intern Med. 2003;138:593-602.

44. Ziegenfuss TN, Hofheins JE, Mendel RW, Landis J, Anderson RA. Effects of a water-soluble cinnamon extract on body composition and features of the metabolic syndrome in pre-diabetic men and women. J Int Soc Sports Nutr. 2006;3:1.

45. Akilen R, Tsiami A, Devendra D, Robinson N. Glycated haemoglobin and blood pressure-lowering effect of cinnamon in multi-ethnic Type 2 diabetic patients in the
UK: a randomized, placebo-controlled, double-blind clinical trial. Diabetic Med. 2010;27:1159-67.

46. Khan A, Bryden NA, Polansky MM, Anderson RA. Insulin potentiating factor and chromium content of selected foods and spices. Biol Trace Elem Res. 1990;24:183-8.

47. Talpur N, Echard B, Ingram C, Bagchi D, Preuss H. Effects of a novel formulation of essential oils on glucose-insulin metabolism in diabetic and hypertensive rats: a pilot study. Diabetes Obes Metab. 2005;7:193-9.

48. Akilen R, Pimlott Z, Tsiami A, Robinson N. Effect of shortterm administration of cinnamon on blood pressure in patients with prediabetes and type 2 diabetes. Nutrition. 2013;29:1192-6.

49. Nasri H, Baradaran A, Shirzad H, Rafieian-Kopaei M. New concepts in nutraceuticals as alternative for pharmaceuticals. Int J Prev Med. 2014;5:1487-99.

50. Gilani AH, Jabeen Q, Khan AU, Shah AJ. Gut modulatory, blood pressure lowering, diuretic and sedative activities of cardamom. J Ethnopharmacol. 2008;115:463-72. 10.1016/j. jep.2007.10.015.

51. Lin RJ, Lo WL, Wang YD, Chen CY. A novel cytotoxic monoterpenoid from the leaves of Cinnamomum subavenium. Nat Prod Res. 2008;22:1055-9.

52. Shan B, Cai YZ, Sun M, Corke H. Antioxidant capacity of 26 spice extracts and characterization of their phenolic constituents. J Agric Food Chem. 2005;53:7749-59.

53. Rao PV, Gan SH. Cinnamon: a multifaceted medicinal plant. Evid Based Complement Alternat Med. 2014;2014.

54. Block W. Cinnamon Improves Oxygen Transport and Blood Pressure. http://www.life-enhancement.com/magazine/ article/2389-cinnamon-improves-oxygen-transport-andblood-pressure. Published 2017.

55. Qin B, Panickar KS, Anderson RA. Cinnamon: potential role in the prevention of insulin resistance, metabolic syndrome, and type 2 diabetes. J Diabetes Sci Technol. 2010;4:685-93.

56. Wainstein J, Stern N, Heller S, Boaz M. Dietary cinnamon supplementation and changes in systolic blood pressure in subjects with type 2 diabetes. J Med Food. 2011;14:1505-10. doi: 10.1089/jmf.2010.0300.

Copyright (C) 2017 The Author(s); Published by Nickan Research Institute. This is an open-access article distributed under the terms of the Creative Commons Attribution License (http://creativecommons.org/licenses/by/4.0), which permits unrestricted use, distribution, and reproduction in any medium, provided the original work is properly cited. 